\title{
Inspiratory and skeletal muscle strength and endurance and diaphragmatic activation in patients with chronic airflow limitation
}

\author{
S Z NEWELL, D K MCKENZIE, S C GANDEVIA
}

From the Unit of Clinical Neurophysiology and Department of Respiratory Medicine, Prince Henry and Prince of Wales Hospitals, and the School of Medicine, University of New South Wales, Sydney, Australia

ABSTRACT To determine whether patients with chronic airflow limitation have a specific alteration in skeletal muscle performance, the strength and endurance of inspiratory and limb muscles were compared in 11 patients with chronic airflow limitation and 11 control subjects during maximal voluntary contractions. Peak inspiratory pressure at observed functional residual capacity (FRC) was significantly less in the patients than in the control subjects (mean 72 (SD 25) $v 93(21) \mathrm{cm} \mathrm{H}_{2} \mathrm{O}$ ), though only two patients had low maximal pressures across a wide volume range. Maximal voluntary torque of the elbow flexor muscles was also reduced in the patients but the difference was not significant $(60$ (17) $v 72(18) \mathrm{Nm}$ ). During the endurance sequence of 18 maximal voluntary contractions (10 s duration, $5 \mathrm{~s}$ rest interval) the decline in peak and average force was less for the inspiratory muscles than for the elbow flexors in both groups. Inspiratory muscle endurance was slightly greater in the patients with chronic airflow limitation than in the control subjects, whereas limb muscle endurance was slightly impaired in the patients. In three patients with chronic airflow limitation, two of whom had low maximal inspiratory pressures at FRC, the ability to drive the diaphragm voluntarily was examined by stimulating the phrenic nerves during maximal inspiratory efforts. Each patient was capable of full activation of the diaphragm during the maximal inspiratory efforts. These results suggest that the relative preservation of inspiratory muscle performance in patients with chronic airflow limitation may be an adaptive response to respiratory "loading."

\section{Introduction}

In patients with chronic airflow limitation the inspiratory muscles are required to overcome increased airway resistance and increased inspiratory elastance as functional residual capacity (FRC) increases. In addition to increasing the elastic load to breathing, this overinflation places the inspiratory muscles at a suboptimal length for generation of muscle tension and reduces the mechanical efficiency of the diaphragm and rib cage. ${ }^{12}$ The inspiratory muscles, especially the diaphragm, may therefore be susceptible to fatigue as a result of increased loading and diminished "capacity" to produce inspiratory force. ${ }^{134} \mathrm{An}$ alternative view is that with chronic loading the

Address for reprint requests: Dr S C Gandevia, Unit of Clinical Neuropshysiology, Department of Neurology, The Prince Henry Hospital, PO Box 233, Matraville, NSW 2036, Australia.

Accepted 1 August 1989 respiratory muscles of patients with chronic airflow limitation may behave like other skeletal muscles and undergo an adaptive response to the functional overload. ${ }^{5-7}$

The inspiratory muscles of healthy subjects have been shown to be highly resistant to the development of fatigue induced by repeated maximal static contractions compared with the expiratory muscles and the muscles acting to flex or extend the elbow joint. ${ }^{8}$ In asthmatic subjects who had frequent episodes of bronchoconstriction the endurance of inspiratory and expiratory muscles was greater than that of control subjects, but the performance of the elbow flexors was similar for the two groups. ${ }^{9}$

In the present study repeated maximal static contractions were used to compare the strength and endurance of inspiratory muscles in patients with chronic airflow limitation with those of control subjects. The performance of a limb muscle was also tested because the illness or drug treatment may have 
resulted in aglobal change of skeletal muscle function. Phrenic nerve stimulation was used to assess the degree of voluntary activation of the phrenic motoneurone pool in some of the patients with chronic airflow limitation. Preliminary results have been presented in brief form. ${ }^{10}$

\section{Methods}

The strength and endurance of the inspiratory muscles and the flexors of the elbow were studied in 11 patients with chronic airflow limitation and 11 control subjects. All subjects were male. The procedures were approved by the institutional ethics committee and informed consent was obtained.

\section{SUBJECTS}

Patients with chronic airflow limitation were included in the study if they had (1) moderate or severe airflow obstruction (FEV $1<60 \%$ of the predicted value) or (2) substantial hyperinflation (FRC $>75 \%$ predicted TLC), or both (see table for their lung function values). None had taken part in a respiratory muscle training programme. No control subject had a history of asthma, other lung disease, or neuromuscular disorders and all had normal spirometric variables and absolute lung volumes. The two groups were well matched for age (50 (SD 15) years for chronic airflow limitation, $48(18)$ years for control), height $(1 \cdot 70$ $(0.07), 1 \cdot 78(0.09), \mathrm{m})$, and weight $(70(8), 75(8) \mathrm{kg})$.

The subjects with chronic airflow limitation were studied when well, usually just before or shortly after discharge from hospital after treatment for an acute exacerbation. None had evidence of right ventricular failure. All subjects completed a questionnaire (see below), performed spirometric tests, underwent measurements of thoracic gas volume and maximal inspiratory pressures at different lung volumes, and,

Pulmonary function (mean (SD) \% predicted unless stated otherwise) in control subjects and patients with chronic airflow limitation (CAL)

\begin{tabular}{lccccc}
\hline & \multicolumn{1}{l}{ Control } & \multicolumn{1}{c}{ CAL } & $p$ \\
\hline FEV $_{1}$ & 103 & $(10)$ & 50 & $(14)$ & $\ddagger$ \\
FVC $_{\text {FEV }} /$ FVC $^{*}$ & 109 & $(8)$ & 83 & $(8)$ & $<0.001$ \\
FRC $_{\text {TLC }}$ & 76 & $(6)$ & 50 & $(13)$ & $<0.001$ \\
Activity scoret & 109 & $(20)$ & 138 & $(32)$ & $\ddagger$ \\
& 105 & $(9)$ & 109 & $(20)$ & NS \\
\hline
\end{tabular}

*Absolute ratio expressed as a percentage

†Activity scale (0-4: see under "Methods") to assess the level of physical activity.

ISignificance levels for differences in FEV 1 and FRC are not reported because abnormality of either variable was a criterion for inclusion in the study.

FEV 1 - forced expiratory volume in one second; FVC-forced vital capacity; FRC-functional residual capacity; TLC-total lung capacity. finally, performed tests of muscle strength and endurance.

\section{QUESTIONNAIRE}

The amount of general activity of subjects during the $\odot$ preceding two months was graded by a five tier scalew that ranged from "sedentary" (score $=0$ ) to $\vec{\circ}$ "endurance training for sporting events" (score = 4). Tobacco consumption was quantified and subjects $\vec{\omega}$ with intercurrent illnesses were detected.

Eight subjects with chronic airflow limitation were $x$ smokers or ex-smokers with a mean (SD) average $\overrightarrow{+}$ consumption of 23 (16) cigarettes a day or $37(25)$ packet years (range 19-92 packet years); six control $\overrightarrow{0}$ subjects were smokers or ex-smokers $\left(9(8)\right.$ cigarettes ${ }_{\omega}$ per day, 10 (8) packet years). Five patients witho chronic airflow limitation (including the three non- smokers) gave a history of severe, poorly controlled $z$ asthma with a mean duration of 12 (range 2-30) years. All patients complained of exertional dyspnoea, nine $\frac{\mathbb{}}{3}$ had a cough, and eight produced sputum for more ${ }_{\Phi}$ than three months a year. All patients had been maintained on long term treatment with beta agonist ${ }_{\infty}$ aerosols or nebuliser solution and oral theophylline. ${ }^{\circ}$ Eight had been having prednisolone (dose ranging from 7.5 to $30 \mathrm{mg}$ daily or alternate days) for more than two months before testing. At the time of the study all but one were taking a higher dose of corticosteroids that they had started while in hospital. $\stackrel{\odot}{\triangle}$ Eight patients were also regular users of inhaled $\overrightarrow{\vec{A}}$ beclomethasone dipropionate $(200-1000 \mu \mathrm{g} / \mathrm{day})$. 을 Questions about intake of standard foods over the previous two months suggested that all subjects had an adequate diet.

\section{PULMONARY FUNCTION TESTS}

Vital capacity was measured with a water sealed ${ }^{\times}$ spirometer. FEV $_{1}$, forced vital capacity (FVC), and 3 . $\mathrm{FEV}_{1} / \mathrm{FVC} \%$ were measured from the best of three maximal expiratory flow-volume manoeuvres. Func- 3 tional residual capacity and total lung capacity (TLC)응 were measured by Boyle's law (panting frequency 1 ? $\mathrm{Hz}$ ) with a pressure compensated, integrated flowo body plethysmograph. The system was calibrated with a 4 litre syringe. Pressure was measured with a 0 differential pressure transducer (Statham PM 131 TC) N calibrated with a water manometer. Predicted values were calculated with standard regressions for white men on the basis of age, height, and weight. " FRC was significantly increased in the patients (table), compatible with the degree of airflow obstruction, but the increase in TLC was not significant (see ref 12). The relation between maximal static inspiratory pressure $\bar{O}$ and absolute lung volume was also determined with $\overrightarrow{\mathbb{D}}$ the subject seated in the body plethysmograph, and $\stackrel{\odot}{\mathbb{\odot}}$ provided with visual feedback of airway pressure. 
Subjects were coached to avoid glottic closure or "cheek artefact," which was detected as a pressure swing accompanied by an inappropriately small change in plethysmographic volume. A 30 minute rest period separated these measurements from the endurance tests.

\section{MEASUREMENT OF STRENGTH AND ENDURANCE}

For each muscle group subjects performed a series of 18 maximal static contractions lasting 10 seconds separated by rest intervals of five seconds (duty cycle $67 \%$ ). Rest periods of about 30 minutes separated tests of the two muscle groups and the order of testing varied between subjects.

Maximal inspiratory efforts were made at measured FRC against a closed airway with the subject seated in the body plethysmograph. Subjects initially performed several brief (1-2 s) maximal inspiratory efforts with visual feedback of airway pressure until reproducible values were obtained. To allow for any drift of the volume signal because of temperature changes during the endurance test, inspiratory capacity was initially determined during several maximal inflations from a stable end expiratory level. Before every static effort subjects inhaled to TLC and then exhaled the appropriate volume before the shutter was closed and the maximal inspiratory contraction begun. Throughout every contraction subjects were continually and loudly exhorted, in a standard way, to maintain a maximal effort by an operator who could not see the force being generated.

For the first three seconds of each contraction absolute lung volume, airway pressure, and time were stored by a microprocessor at a sampling rate of 100 $\mathrm{Hz}$. Subsequently values were sampled at $100 \mathrm{~Hz}$ and averaged for periods of $100 \mathrm{~ms}$, and the averaged values were stored. The average pressure sustained throughout the contraction was calculated on line and stored with the initial peak pressure and the initial absolute lung volume.

As there was some variation in the absolute lung volumes at which individual contractions were started (usually within $400 \mathrm{ml}$ ) the maximal static pressurevolume relationship for each subject was used to correct the pressure measurements. A curve of best fit was drawn by hand through the points. Graphical methods were used to derive scaling factors for the expected change in maximal inspiratory pressure for $100 \mathrm{ml}$ changes in absolute lung volume above and below the mean initial volume for the series of 18 contractions. The appropriate scaling factor was then applied if necessary to the values for peak and average pressure for each contraction. ${ }^{13}$ The magnitude of this scaling factor clearly depended on the position of FRC in relation to the curve of static pressure and lung volume (see, for example, fig 1). For most subjects the difference in maximal inspiratory pressure for a change in lung volume of $100 \mathrm{ml}$ above or below FRC is less than $5 \mathrm{~cm} \mathrm{H}_{2} \mathrm{O}$.

An identical protocol was followed for maximal contractions of the elbow flexors, performed with the subject seated comfortably at a table and the dominant arm fixed to a vertical isometric myograph. The forearm was placed supine and the elbow flexed at 90 degrees with the upper arm held horizontal by fixation of the shoulder. Torque (which is directly proportional to force) was measured continuously. ${ }^{8}$ Data from limb contractions were analysed by measuring the initial peak force and the average force maintained throughout each contraction.

The strength of both muscle groups (maximal inspiratory pressure and torque of the elbow flexors) was taken as the largest pressure (or torque) achieved in the first three contractions of the endurance test. This peak always occurred within the first two to three seconds of a contraction and was within $5 \%$ of the maximal value achieved in the preliminary trials. For both limb and inspiratory muscles indices of endurance were calculated as the ratio between the peak (or average) force in the better of the last two contractions and the peak (or average) value in the best of the first three contractions. These indices are considered measures of endurance and are expressed as percentages.

During the inspiratory endurance test oxygen was released into the breathing circuit at $6 \mathrm{l} / \mathrm{min}$ for all subjects. During inspiratory resistive loading in healthy subjects a reduction in the concentration of inspired oxygen appears to decrease endurance time, ${ }^{14-16}$ whereas breathing $100 \%$ oxygen increases endurance time. ${ }^{17}$ In contrast, Gandevia et $a l^{8}$ found that supplemental oxygen made no difference in healthy subjects to the endurance profile in a series of maximal static inspiratory efforts. Patients with severe pulmonary disease, however, had difficulty in maintaining the maximal inspiratory pressure for the required 10 seconds without supplemental oxygen.

\section{ASSESSMENT OF DIAPHRAGMATIC ACTIVATION}

Additional experiments were performed on three patients with chronic airflow limitation, two of whom were selected because their maximal inspiratory pressures were below the normal range (see under "Results"). Oesophageal, gastric, and transdiaphragmatic pressures were recorded with a multilumen gastro-oesophageal catheter, which also enabled diaphragmatic electromyographic activity (EMG) to be measured via $\mathrm{Ag}-\mathrm{AgCl}$ ring electrodes 1 and $6 \mathrm{~cm}$ proximal to a stabilising balloon at the gastro-oesophageal junction. ${ }^{18}$ All EMG signals were amplified ( $\times 1000-5000)$ and filtered (band width $3 \cdot 2-1 \cdot 6 \mathrm{KHz}$ ). The phrenic nerve was stimulated at or below the level 
of the cricoid cartilage (bilaterally in one patient and unilaterally in two) with adjustable probe electrodes mounted on movable stages attached to a firm neck brace. The anode was fixed to the manubrium. Rectangular pulses (100-200 $\mu$ s duration, up to $400 \mathrm{v})$ were delivered while the electrode position was adjusted so that supramaximal stimuli (as judged by the diaphragmatic compound muscle action potential) were delivered to the phrenic nerve with minimal spread to the brachial plexus. Stimuli delivered during strong contractions were 1.3-2 times the stimulus intensity required to produce a maximal muscle action potential at rest at FRC.

Subjects performed brief maximal inspiratory efforts against a closed airway, similar to those they had performed during the endurance test. Several trials were undertaken without interpolated stimuli and the size of the maximal inspiratory pressure was compared with that obtained during the endurance test. Then at least five maximal attempts were made with interpolation of supramaximal unilateral or bilateral phrenic nerve stimulation. Evoked pressure changes were measured after each attempt from oscilloscope records at high gain. Data were also recorded on FM tape for subsequent analysis. The resolution of the technique was $0.5 \mathrm{~cm} \mathrm{H}_{2} \mathrm{O}$ with the use of a voltage clamp circuit. ${ }^{19}$ Failure to detect an evoked response suggests that at least $95 \%$ of the stimulated muscle was fully activated by the voluntary effort.

\section{STATISTICS}

Unless stated otherwise, results are reported as means with standard deviations in parentheses. Differences $\stackrel{\text { की }}{+}$ in strength and the indices of endurance (defined? above) between groups of subjects were assessed by unpaired two tailed $t$ tests. Differences between thes relative performance of the two muscle groups weres tested with paired $t$ tests. Results were accepted as statistically significant if $p<0.05$. The influence of chronic airflow limitation on muscle performance was. also tested for both muscle groups by analysis of variance and covariance with the MANOVA pro-o gramme from SPSSx (Statistical Package for Socia $\vec{x}$ Sciences). To control for variation in strength between: subjects, values were normalised to the largest of the first three contractions. The natural logarithm of the normalised value was used to satisfy the linear modelo of the statistical programme.

UNITS

All respiratory pressures are given in absolute $\mathrm{cm}_{2} \mathrm{O}$. These values are converted to $\mathrm{kPa}$ by multiplying them by 0.098 .

\section{Results}

MAXIMAL INSPIRATORY PRESSURE-VOLUME RELATIONSHIP

Individual results for the relation between maximas inspiratory pressure and absolute lung volume aren plotted in relation to each subject's observed TLC ino figure 1. Two patients had values for maximal inspiratory pressure (MIP) below the observed controt) range at all lung volumes but only one had values outside the accepted normal range. ${ }^{2021}$ The latter

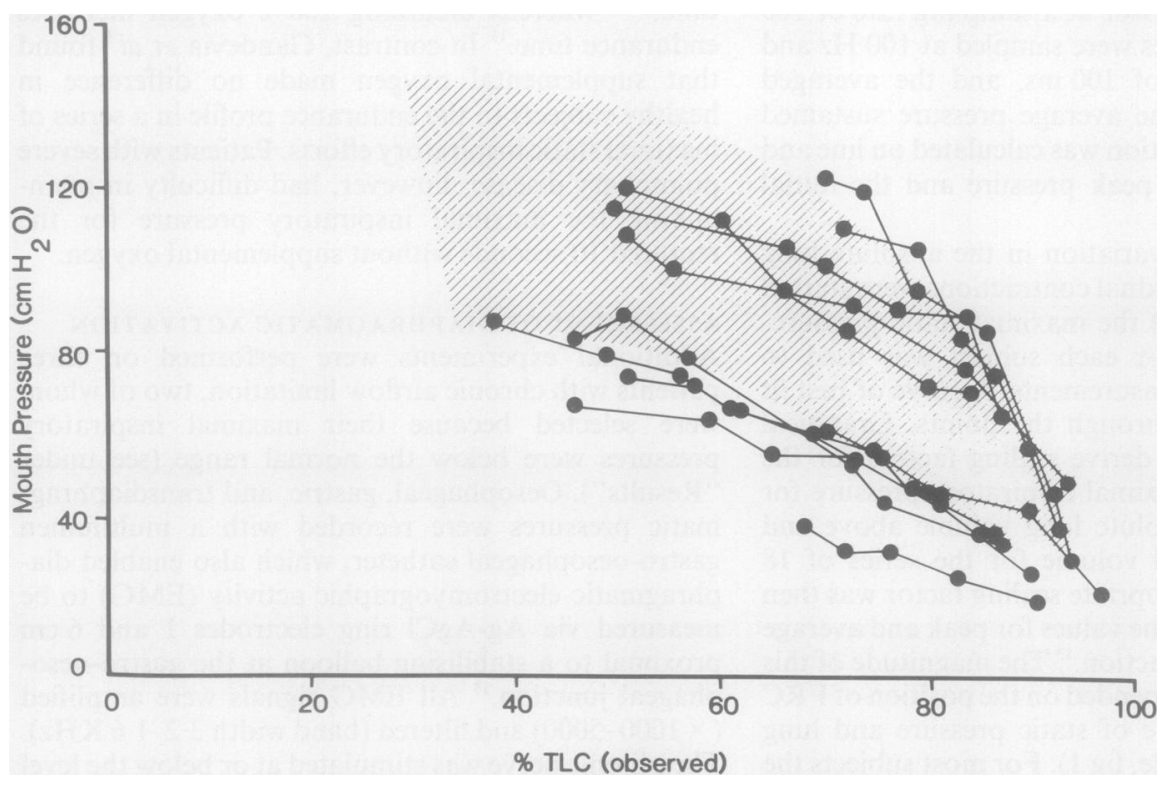

Fig 1 Individual results for the relation between maximal inspiratory pressure and absolute lung volume in patients with chronic airflow limitation, plotted relative to each patient's observed total lung capacity (TLC). The shaded area represents the observed range for control subjects. 
patient had severe chronic airflow limitation and emphysema and had been having long term maintenance prednisolone. This subject also had the lowest value for elbow flexor strength (fig 2). Three patients with values for maximal inspiratory pressure at the extremes of the observed range (two low, one high) subsequently underwent electrophysiological studies of voluntary activation of the diaphragm (see below).

\section{STRENGTH AND ENDURANCE}

The mean (SD) maximal inspiratory pressure (MIP), taken as the peak of the best of the first three contractions in the endurance test, was $72(25) \mathrm{cm} \mathrm{H}_{2} \mathrm{O}$ at FRC for subjects with chronic airflow limitation, significantly less than that for control subjects (93 (21) $\mathrm{cm} \mathrm{H}_{2} \mathrm{O} ; \mathrm{p}<0.05$, see also figure 2). Maximal elbow flexor torque $(60(17) \mathrm{Nm})$ in patients with chronic airflow limitation was less than that for control subjects (72 (18) $\mathrm{Nm})$, though the difference was not statistically significant. The maximal inspiratory pressure at FRC showed a significant positive correlation with maximal elbow flexor torque (fig 2).

Data from a typical sequence of contractions are shown in figure 3. During the series of 18 contractions with a duty cycle of $67 \%$ (see under "Methods") the peak and average pressures produced by the inspiratory muscles declined, but in all subjects studied there was a greater relative decline in the peak and average force produced by the elbow flexors $(p<0.001$; figs 4 and 5). The results for control subjects are similar to those obtained in previous studies that used an identical protocol. ${ }^{913}$

For the elbow flexors peak and average force were consistently better maintained by the control subjects (fig 4) but the difference at the end of the test was small

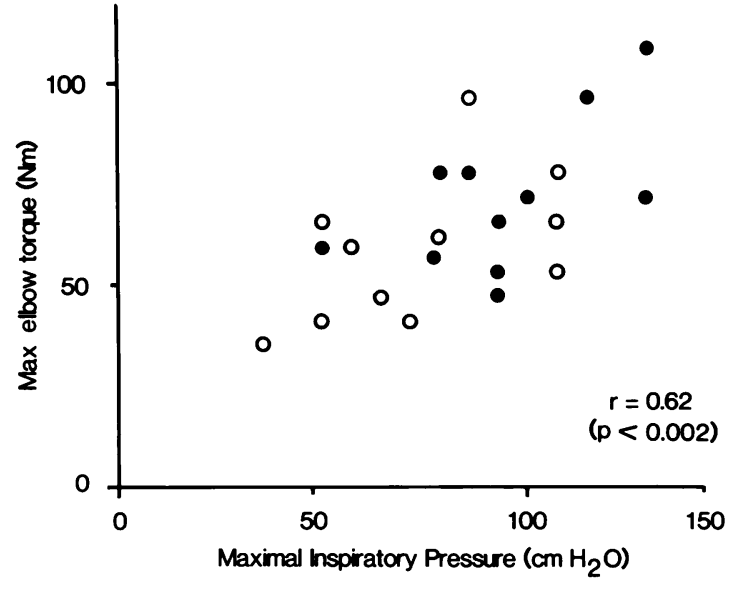

Fig 2 Individual results for maximal inspiratory pressure at functional residual capacity for patients with chronic airflow limitation (open circles) and control subjects (closed circles) plotted against each subject's maximal torque exerted by the elbow flexors.

(control $60 \%(9 \%)$ of the initial value, chronic airflow limitation $57 \%(12 \%))$. By contrast, inspiratory muscle performance was better in the patients than in the control subjects (fig 5). The difference in relative decline of pressure was small but consistent (chronic airflow limitation $93 \%(14 \%)$ of the initial value, control $88 \%(15 \%))$. Analyses of variance with data for peak and average force from the 18 contractions showed significantly better performance of the inspiratory muscles of the patients with chronic airflow limitation than of the control subjects $(p<0.01$ for both peak and average sustained pressure). In the

INSPIRATORY

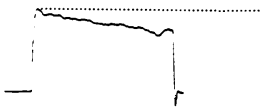

1

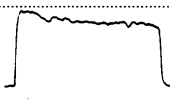

2

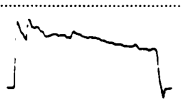

17

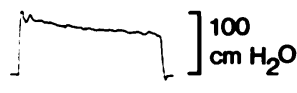

18

\section{ELBOW FLEXORS}

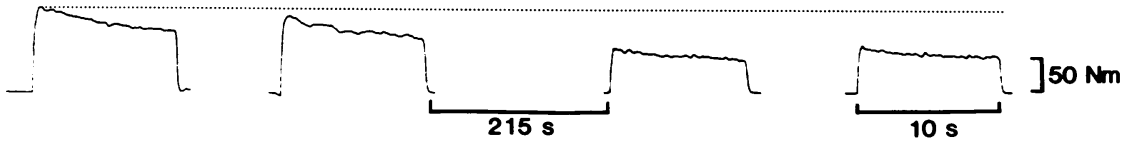

Fig 3 Records from a typical study in a control subject. Repeated maximal static contractions of the inspiratory muscles (upper panel) at functional residual capacity and of the elbow flexors (lower panel). The contractions lasted 10 seconds with rest intervals of five seconds (that is, a duty cycle of 67\%). Peak pressure or torque was achieved in the first two seconds of any contraction. After 18 contractions the decline in peak and average sustained force was less for the inspiratory muscles than for the elbow flexors. Each vertical calibration bar indicates the range from zero to the specified pressure or torque. 
ELBOW FLEXORS

PEAK

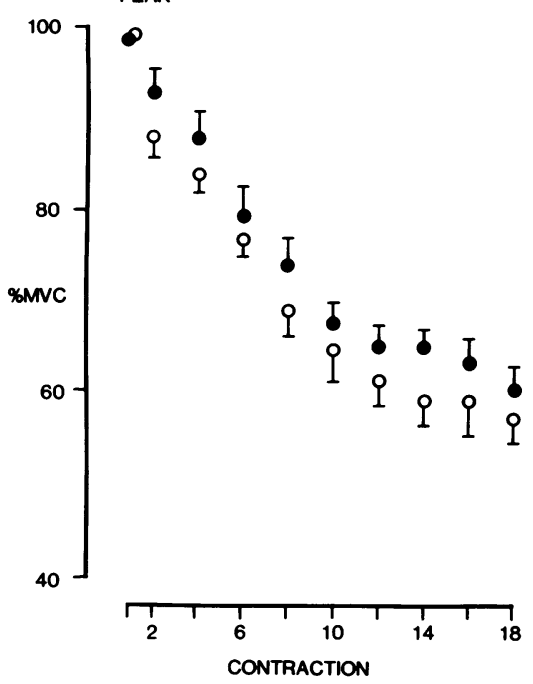

AVERAGE

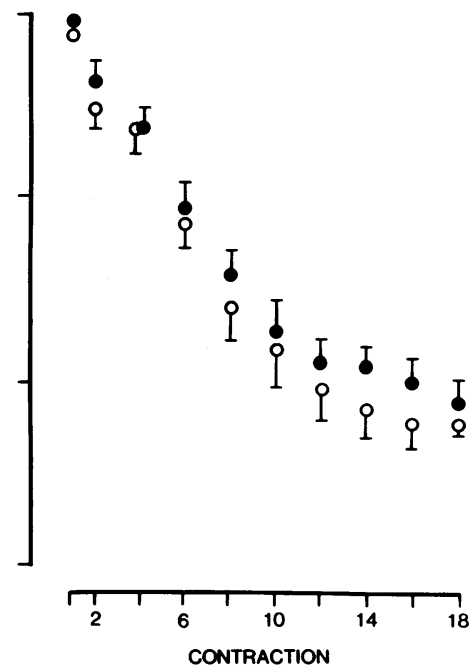

Fig 4 Maximal performance of the elbow flexors tested with 18 maximal static contractions of 10 seconds' duration separated by rest intervals of five seconds in 11 subjects with chronic airflow limitation (open circles) and 11 control subjects (closed circles). Each data point represents the mean and SEM for the peak force (left panel) and the average force sustained for 10 seconds (right panel) in the better of each two consecutive contractions, expressed as a percentage of that attained in the best of the first three contractions. The first two contractions are depicted separately. There was a trend for elbow flexor torque to be slightly better maintained by the control subjects.

\section{INSPIRATORY}

PEAK

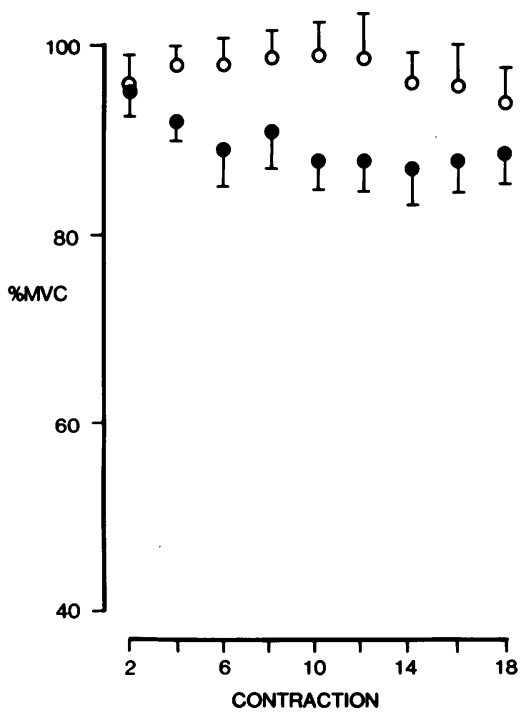

AVERAGE

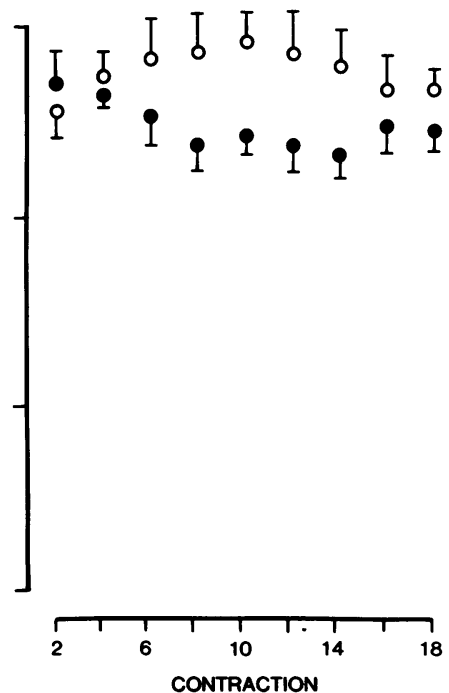

Fig 5 Maximal performance of the inspiratory muscles tested with 18 maximal inspiratory contractions of 10 seconds' duration separated by rest intervals of five seconds in 11 subjects with chronic airflow limitation (open circles) and 11 control subjects (closed circles). Each data point represents the mean and SEM for the peak pressure (left panel) and average pressure sustained for 10 seconds (right panel) in the better of each two consecutive contractions, expressed as a percentage of that attained in the best of the first three contractions. There was a clear trend for inspiratory pressure to be better maintained by the subjects with chronic airflow limitation. 

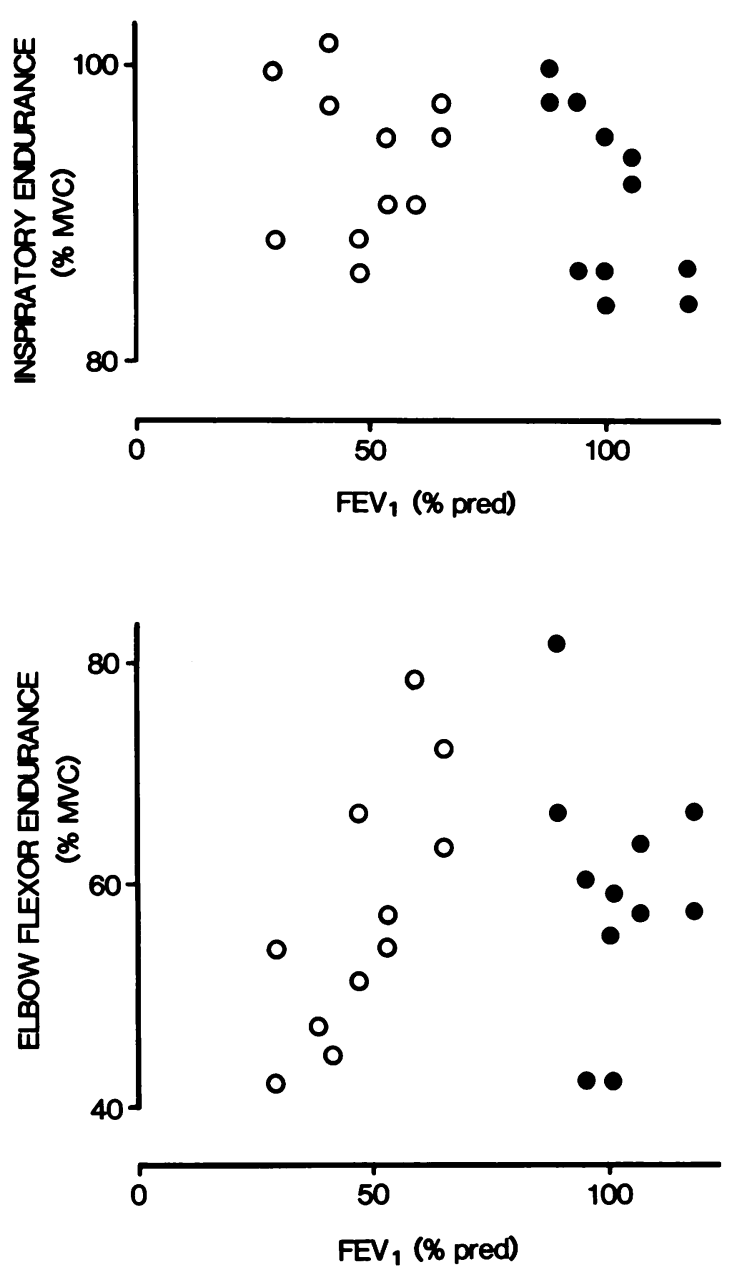

Fig 6 Endurance of the inspiratory muscles (above) and of the elbow flexors (below) for patients with chronic airflow limitation (open circles) and controls (closed circles) plotted in relation to each subject's FEV (\% predicted). There was a significant positive correlation for elbow flexor endurance and $F E V_{1}(\%$ predicted) in the patients with chronic airflow limitation $(p<0.01)$.

analysis of covariance the influence of factor (chronic airflow limitation or control) was also significant ( $p<$ 0.05 ). For the elbow flexors analysis of variance showed significantly better performance in the control group ( $p<0.05$ for average torque).

Correlations were also sought between the indices of the severity of airflow obstruction (that is, FEV $\mathrm{FEV}_{1} / \mathrm{FVC} \%$, and FRC, all expressed as percentages of the predicted values) and the measurements of strength and the indices of endurance for the two muscle groups. There was no correlation between any of these measures of airflow obstruction and the indices of endurance for the inspiratory muscles (fig 6). There was, however, a significant positive correlation between elbow flexor endurance and both FEV,\% predicted (p < 0.01, fig 6) and FEV $_{1} /$ FVC\% $(p<$ 0.05 ) in the patients with chronic airflow limitation.

\section{DIA PHRAGMATIC ACTIVATION}

To determine whether the ability to activate the phrenic motoneurone pool voluntarily is impaired in chronic airflow limitation three patients underwent electrophysiological studies. One (age 60, FEV $144 \%$ predicted) had an extremely low value for maximal inspiratory pressure $\left(40 \mathrm{~cm} \mathrm{H}_{2} \mathrm{O}\right.$ ), another (age 78 , $\mathrm{FEV}_{1} 30 \%$ predicted) was at the low end of the normal range $\left(60 \mathrm{~cm} \mathrm{H}_{2} \mathrm{O}\right)$, and the third (age $30, \mathrm{FEV}_{1} 28 \%$ predicted) was at the upper end of the control range $\left(120 \mathrm{~cm} \mathrm{H}_{2} \mathrm{O}\right)$. All had severe airflow obstruction and substantial hyperinflation (FRC 159\%, 184\%, and $199 \%$ predicted). When restudied each subject attained a maximal inspiratory pressure within $5 \%$ of that observed during the previous endurance test.

As judged by the failure of supramaximal stimuli of the phrenic nerve or nerves to produce any increase in transdiaphragmatic pressure at the appropriate latency, the three subjects were capable of full neural activation of the diaphragm. Results of representative trials in one subject are shown in figure 7. During five attempts the success rate for maximal activation of the phrenic motoneurone pools (with single stimuli) ranged from $40 \%$ to $60 \%$ between the subjects.

\section{Discussion}

In the patients with chronic airflow limitation maximal static inspiratory pressure at FRC was $23 \%$ lower than that of the control subjects $(p<0.05)$ and there was a smaller reduction in maximal static torque of the elbow flexors $(17 \%)$ that was not statistically significant. There were small differences between the subject groups in the relative endurance of the two muscle groups, with inspiratory pressure slightly better maintained by the patients with chronic airflow limitation, and elbow torque by the control subjects. The substantial difference in endurance between the two muscle groups in both the patients and the control subjects has been documented and discussed previously. ${ }^{89} 132526$ The enhanced endurance was attributed, in part, to relative preservation of intramuscular perfusion of the diaphragm or intercostal muscles, or both, during loaded inspiratory efforts. ${ }^{1326}$

The use of repeated maximal static contractions to compare endurance properties of different muscles may be invalid if the muscles are not activated maximally during voluntary contractions. In healthy 


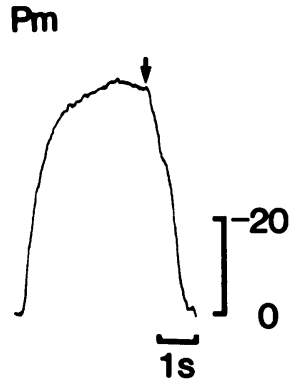

(a)

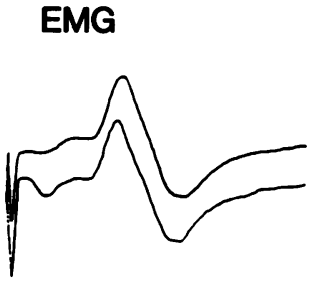

MVC
Pdi

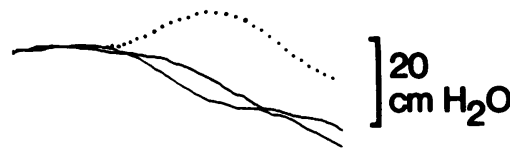

$50 \mathrm{~ms}$

(b)

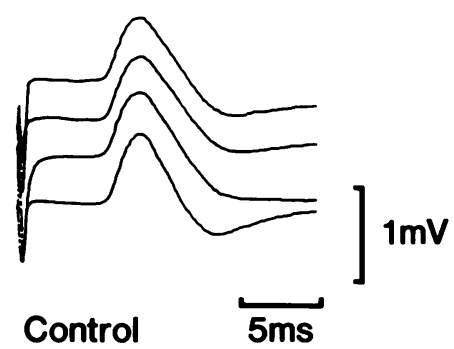

Fig 7 (a) Left: Mouth pressure (Pm) during maximal inspiratory effort with supramaximal stimulation of left phrenic nerve at arrow. Right: Transdiaphragmatic pressure (Pdi) change evoked by supramaximal stimulation of the left phrenic nerve during two attempted maximal voluntary contractions $(M V C)$, including that on the left. Note the different time bases. The two responses are superimposed for visual effect, though the absolute Pdi at the time of stimulation varied slightly $\left(45-50 \mathrm{~cm} \mathrm{H}_{2} \mathrm{O}\right)$. The broken superimposed line is the average of four twitch responses shown at the same gain, which was obtained with the patient relaxed at $F R C$ - that is, resting Pdi about $5 \mathrm{~cm} \mathrm{H}_{2} \mathrm{O}$. No evoked response was seen during maximal effort. (b) Left: Compound muscle action potentials (CMAP) from the diaphragm recorded with oesophageal electrodes during the two maximum voluntary contractions (MVC) depicted above right. Right: Maximal compound muscle action potentials at rest (control) recorded during the average of resting twitches displayed above right (dotted line). Calibration applies to both panels. The peak to peak amplitude of the CMAP was unaltered during maximal voluntary contractions but there was a slight change in shape of the action potential.

subjects maximal activation of the relevant motoneurone pool has been documented for several limb muscles, including the elbow flexors ${ }^{223}$ and diaphragm. ${ }^{24-26}$ If the subjects with chronic airflow limitation were not able to activate the diaphragm maximally during the endurance test, it would not be surprising that endurance appeared to be enhanced. Supramaximal stimulation of the phrenic nerve or nerves, however, showed that complete voluntary activation of the phrenic motoneurone pool had been achieved in these three patients (who included two with the lowest values for maximal inspiratory pressure). When the sensitivity of this test was investigated recently, ${ }^{1923}$ the results suggested that failure to activate $2 \%$ of the stimulated muscle mass voluntarily can be detected during twitch interpolation.

\section{PERFORMANCE OF LIMB MUSCLES IN CHRONIC} AIRFLOW LIMITATION

Several factors may have contributed to the reduction in limb muscle performance in the patients. As expected, the general level of activity of the patients wasos significantly less than that of the control group. Secondly, metabolic factors may have contributed ton the poor performance. Slight changes in enzyme $\omega$ activities have been found in the muscles of patients with chronic airflow limitation. ${ }^{27}$ Thirdly, cardiovascular output or oxygen delivery to the muscles (orof both) may have been decreased in the patients. Fourthly, although the mean weight for subjects in thetwo groups was similar (see under "Methods"), thereop may have been an alteration in body habitus or usage $\frac{?}{8}$ of upper body musculature, or both, in the patients 
with chronic airflow limitation. Six patients had been taking long term oral prednisolone, which may have contributed to a reduction in proximal muscle strength. Malnutrition and decreased muscularity (including that of the diaphragm) have been reported in some studies of patients with advanced chronic airflow limitation. ${ }^{28}$ We found that limb muscle endurance in patients with chronic airflow limitation was correlated positively with airway function, as estimated by measurement of $\mathrm{FEV}_{1}$ (and $\mathrm{FEV}_{1} / \mathrm{FVC}$ ). This interesting finding does not, however, distinguish between the possible mechanisms.

\section{INSPIRATORY MUSCLE STRENGTH IN CHRONIC}

AIRFLOW LIMITATION

Estimates of respiratory muscle strength in patients with pulmonary disease have yielded conflicting results, largely because maximal static respiratory pressures are also influenced by changes in lung volume and chest shape. Byrd and $\mathrm{Hyatt}^{29}$ claimed that the strength of respiratory muscles was increased in patients with chronic obstructive lung disease when the values were related to predicted rather than the observed absolute lung volume. Braun and Rochester ${ }^{30}$ allowed for differences between patients and control subjects in the passive recoil pressure of the respiratory system and concluded that maximal inspiratory pressure was reduced in the patient group. They claimed that the reduction stemmed primarily from the mechanical disadvantage of the inspiratory muscles and that inspiratory muscle force was further compromised by generalised muscle weakness in severe chronic obstructive pulmonary disease. Other studies have also reported decreased inspiratory pressures for patients with severe chronic obstructive lung disease. ${ }^{202131}$ The latter results would be consistent with recent findings of reductions in muscle fibre size in the diaphragm but not intercostal muscles of patients with emphysema. ${ }^{32}$ By contrast, studies of non-obese asthmatic subjects have shown normal or increased values for maximal inspiratory pressure, despite the presence of hyperinflation. ${ }^{93}$

In the present study the overall reduction in maximal inspiratory pressure at FRC in the patients was similar in relative terms to that observed for elbow flexors. FRC, however, was significantly increased in the subjects with chronic airflow limitation. Only one patient had values that were well below the control range when maximal inspiratory pressure was plotted as a function of observed TLC. If the reduction in strength of the elbow flexors reflected a global alteration in skeletal muscle force, the present results suggest that the inspiratory muscles of the patients may have been spared.
INSPIRATORY MUSCLE ENDURANCE IN CHRONIC AIRFLOW LIMITATION

Despite claims that the respiratory muscles of patients with obstructive pulmonary disease are unduly prone to fatigue, there have been few direct studies of respiratory muscle endurance in such patients. Evidence from this and a previous study does not support the idea that inspiratory muscles are especially susceptible to fatigue in patients with obstructive disorders. McKenzie and Gandevia ${ }^{9}$ found in asthmatic subjects with frequent episodes of wheeze that the strength of the inspiratory and expiratory muscles was normal and the endurance of both muscle groups was enhanced. The current study provides the first evidence that not only is there no specific impairment of inspiratory muscle endurance in subjects with chronic airflow limitation but there may be slight enhancement. This contrasts with the slight impairment in endurance of the elbow flexors of patients with chronic airflow limitation.

The relative sparing of inspiratory muscle performance in subjects with chronic airflow limitation could reflect the relative increase in FRC and consequent shortening of inspiratory muscles. When limb muscles contract at a short muscle length there is a decrease in maximal force (the length-tension effect) and an enhancement of endurance ${ }^{13}$ at least as great as that documented here for the inspiratory muscles of patients with chronic airflow limitation. McKenzie and Gandevia ${ }^{13}$ have shown, however, that the endurance of the inspiratory muscles of normal subjects is slightly less during repeated contractions at a high lung volume (that is, with shortened inspiratory muscles) than during contractions at FRC. This apparently paradoxical result for the inspiratory muscles was attributed to variations in intramuscular perfusion between the two muscles and the influence of pleural pressure on diaphragmatic blood flow (see McKenzie and Gandevia ${ }^{13}$ for full discussion). Given that some impairment of inspiratory muscle endurance might have been expected in the patients owing to hyperinflation, the small enhancement documented in the present study is especially notable. Taken with the evidence for a global impairment of skeletal muscle performance, the present results suggest that the inspiratory muscles of the patients may have been trained for endurance by the loads imposed by the pulmonary disorder.

This study was supported by the Asthma Foundation of New South Wales and the National Health and Medical Research Council of Australia. We are grateful to Professor $\mathbf{H ~ J ~ H ~ C o l e b a t c h ~ f o r ~ c r i t i c a l ~}$ comment on the manuscript. 
References

1 Roussos CS, Macklem PT. The Respiratory Muscles. $N$ Engl J Med 1982;307:786-97.

2 Arora NS, Rochester DF. COPD and human diaphragm muscle dimensions. Chest 1987;91:719-24.

3 Rochester DF, Braun NMT, Arora NS. Respiratory muscle strength in chronic obstructive pulmonary disease. Am Rev Respir Dis 1979;199(suppl):151-4.

4 Bellemare F, Grassino A. Force reserve of the diaphragm in patients with chronic obstructive pulmonary disease. J Appl Physiol 1983;55:8-15.

5 Holloszy JO, Booth FW. Biochemical adaptations to endurance exercise in muscle. Ann Rev Physiol 1976; 38:273-91.

6 Hudlická O. Effect of training on macro- and microcirculatory changes in exercise. Exercise and Sport Sci $\operatorname{Rev}$ 1980;6:181-230.

7 Saltin B, Gollnick PD. Skeletal muscle adaptability: significance for metabolism and performance. In: Handbook of physiology. Section 10: Skeletal muscle. Bethesda, Maryland: American Physiological Society, 1983:555-631.

8 Gandevia SC, McKenzie DK, Neering IR. Endurance properties of respiratory and limb muscles. Respir Physiol 1983;53:47-61.

9 McKenzie DK, Gandevia SC. Strength and endurance of inspiratory, expiratory and limb muscles in asthma. Am Rev Respir Dis 1986;134:999-1004.

10 McKenzie DK, Newell SZ, Gandevia SC. Strength and endurance of inspiratory muscles in chronic airflow limitation. Proc Aust Physiol Pharmacol Soc 1988; 1:239P.

11 Quanjer PhE, ed. Standardized lung function testing. Report working party, standardization of lung function tests. Bull Eur Physiopathol Respir.1983;19(suppl 5):1-95.

12 Lavietes MH, Grocela JA, Maniatis T, Potulski F, Ritter AB, Sunderarm G. Inspiratory muscle strength in asthma. Chest 1988;93:1043-7.

13 McKenzie DK, Gandevia SC. Influence of muscle length on human inspiratory and limb muscle endurance. Respir Physiol 1987;67:171-82.

14 Roussos CS, Macklem PT. Diaphragmatic fatigue in man. J Appl Physiol 1977;43:189-97.

15 Jardim J, Farkas G, Prefaut C, Thomas D, Macklem PT, Roussos C. The failing inspiratory muscles under normoxic and hypoxic conditions. Am Rev Respir Dis 1981;124:274-9.

16 Koulouris N, Moxham J, Barnes N, Gray B, Heaton R, Green M. Effect of hypoxia on respiratory and limb muscle endurance [abstract]. Thorax 1984;39:714.

17 Pardy RL, Bye PTP. Diaphragmatic fatigue in normoxia and hyperoxia. J Appl Physiol 1984;58:738-42.
18 McKenzie DK, Gandevia SC. Phrenic nerve conduction time and twitch pressures of the human diaphragm. to Appl Physiol 1985;58:1496-504.

19 Hales JP, Gandevia SC. Assessment of voluntary con $\overline{\overline{\bar{n}}}$ traction with twitch interpolation: an instrument to measure twitch responses. J Neurosci Meth 1988;25. 97-102.

20 Decramer M, Demedts M, Rochette F, Billiet L. Maximal transrespiratory pressures in obstructive lung disease. Bull Eur Physiopathol Respir 1980;16:479-90. $\vec{\omega}$

21 Gibson GJ, Clark E, Pride NB. Static transdiaphragmatico. pressures in normal subjects and in patients with $\vec{\sim}$ chronic hyperinflation. Am Rev Respir Dis 1981;124 685-9.

22 Bellemare F, Woods JJ, Johansson R, Bigland-Ritchie BMotor-unit discharge rates in maximal voluntary con tractions of three human muscles. J Neurophysiol 1983이 50:1380-92.

23 Gandevia SC, McKenzie DK. Activation of human muscles at short muscle lengths during maximal static efforts. J Physiol (Lond) 1988;407:599-613.

24 Bellemare F, Bigland-Ritchie B. Assessment of human diaphragm strength and activation using phrenic nerve stimulation. Respir Physiol 1984;58:263-77.

25 Gandevia SC, McKenzie DK. Activation of the humandiaphragm during maximal static efforts. $J$ Physio (Lond) 1985;367:45-56.

26 Gandevia SC, McKenzie DK. Human diaphragmatio endurance during different maximal respiratorye efforts. J Physiol (Lond) 1988;395:625-38.

27 Sánchez J, Bastien C, Medrano G, Riquet M, Derennē JP. Metabolic enzymatic activities in the diaphragm of normal men and patients with moderate chronic obstructive pulmonary disease. Bull Eur Physiopatho Respir 1984;20:535-40.

28 Arora NS, Rochester DF. Effect of body weight and muscularity on human diaphragm muscle mass, thick $=$ ness and area. J Appl Physiol 1982;52:64-70.

29 Byrd RB, Hyatt RE. Maximal respiratory pressures in chronic obstructive lung disease. Am Rev Respir Dis유 1968;98:848-56.

30 Braun NMT, Rochester DF. Respiratory muscle func: tion in chronic obstructive pulmonary disease (COPD) Am Rev Respir Dis 1977;115:91.

31 Marrazzini L, Vezzoli F, Rizzato G. Intrathroacic pres-3 sure development in chronic airways obstruction. Appl Physiol 1974;37:575-8.

32 Sánchez J, Derenne JP, Debesse B, Riquet TM, Mono $H$. Typology of the respiratory muscles in normal menand in patients with moderate chronic respiratory disease. Bull Eur Physiopathol Respir 1982;18:901-14.

33 Nickerson BG, Richards W, Wang C, Keens TGN Increased ventilatory muscle strength and endurance in children with asthma and cystic fibrosis [abstract]. Fed Proc 1981;40:540A. 